\title{
Evaluation of Layered Double Hydroxide Synthesised from a Green Biogenic Precursor for Phosphate Removal: Characterisations and Isotherms
}

\author{
Ruth Olubukola Ajoke Adelagun ${ }^{1}$, Nurudeen Abiola Oladoja ${ }^{2}$, Isaac Ayodele Ololade ${ }^{2}$, \\ Adeniyi Samson Adeyemo \\ ${ }^{1}$ Department of Chemical Sciences, Federal University Wukari, Wukari, Nigeria \\ ${ }^{2}$ Department of Chemical Sciences, Adekunle Ajasin University, Akungba - Akoko, Ondo, Nigeria
}

Email address:

jemiruth2009@yahoo.com (R. O. A. Adelagun)

\section{To cite this article:}

Ruth Olubukola Ajoke Adelagun, Nurudeen Abiola Oladoja, Isaac Ayodele Ololade, Adeniyi Samson Adeyemo. Evaluation of Layered Double Hydroxide Synthesised from a Green Biogenic Precursor for Phosphate Removal: Characterisations and Isotherms. American Journal of BioScience. Vol. 5, No. 2, 2017, pp. 13-24. doi: 10.11648/j.ajbio.20170502.11

Received: February 8, 2017; Accepted: March 13, 2017; Published: March 22, 2017

\begin{abstract}
CaCr}$ LDH materials were synthesized by the co-precipitation method, using Gastropod shell as a biogenic source of $\mathrm{Ca}^{2+}$. The mineralogical, surficial morphology and elemental composition analysis of the materials showed characteristics typical of hydrotalcite-like materials, composed of $\mathrm{Ca}, \mathrm{Cr}, \mathrm{O}, \mathrm{C}$ and $\mathrm{Cl}$. Batch equilibrium adsorption studies showed that phosphate sorption on the LDH reached equilibrium within 5 min with about $98 \%$ removal. The sorption of phosphate was well described by the Langmuir isotherm model. The monolayer adsorption capacity of the CaCr LDH for phosphate was $142.86 \mathrm{mg} / \mathrm{g}$. Mechanistic studies of phosphate removal by the LDHs was elucidated via instrumental analysis, vis-a viz, SEMEDX, XRD and FTIR. Results revealed that phosphate was removed via the combination of ion exchange and precipitation. It could be inferred that $\mathrm{CaCr}$ LDH synthesised using Gastropod shell as a biogenic source of $\mathrm{Ca}^{2+}$ is a suitable adsorbent for phosphate removal from aqua system.
\end{abstract}

Keywords: Phosphate, Layered Double Hydroxide, Characterisation, Gastropod Shell, Isotherms

\section{Introduction}

Layered double hydroxides (LDH) are laminar anionic clay materials also known as hydrotalcite compounds and characterized with high exchange capacity [1]. The structure of layered double hydroxides is patterned after the brucitelike structure of $\mathrm{Mg}(\mathrm{OH})_{2}$ which consists of $\mathrm{Mg}^{2+}$ octahedrally surrounded by $\mathrm{OH}^{-}$. LDH chemical composition is described by the formular:

$$
\mathrm{M}_{1-x}^{2+} \mathrm{M}_{x}^{3+}(\mathrm{OH})_{2}\left(\mathrm{~A}^{n-}\right)_{x / n} \cdot \mathrm{mH}_{2} \mathrm{O}
$$

The $\mathrm{M}_{1-x}{ }^{2+} \mathrm{M}_{x}^{3+}(\mathrm{OH})_{2}$ represents the layer, while $\left(\mathrm{A}^{n-}\right.$ )$_{x / n} \cdot m \mathrm{H}_{2} \mathrm{O}$ represents the interlayer composition. $\mathrm{M}^{2+}$ and $\mathrm{M}^{3+}$ are divalent and trivalent cations with ionic radius ranging between $0.65-0.80 \AA$ and $0.62-0.69 \AA$, respectively. Varying the $\mathrm{M}^{2+} / \mathrm{M}^{3+}$ ratio alters the charge density and the anion exchange capacity of the LDHs [2]. The net positive charge of the LDH is counterbalanced by the exchangeable interlayer anion $\mathrm{A}^{\mathrm{n}-}$, in the interlamellar region which could be any anion such as $\mathrm{CO}_{3}{ }^{2-}, \mathrm{NO}_{3}{ }^{-}, \mathrm{Cl}^{-}$with valence $n$ that could be exchanged with other anions [3-4]. $m$ is the amount of water in moles, present in the $\mathrm{LDH} . \mathrm{M}^{2+}, \mathrm{M}^{3+}, x$, and $\mathrm{A}^{\mathrm{n}-}$ identities may vary over a wide range, thus giving rise to a large class of isostructural materials with different physicochemical properties [5-6]. The stability of the structure is ensured by the hydrogen bonds between the hydroxyl groups of octahedral sheets and the intercalated species, anions and water molecules [7]. Due to the high ionexchange properties of the interlayer anions, LDHs have attracted high research interests as promising materials for the selective uptake of polyatomic anions including phosphate from aqueous system [8]. In the present studies, $\mathrm{CaCr}$ LDH synthesised using Gastropods shell (a biogenic precursor) as $\mathrm{Ca}^{2+}$ source was evaluated for phosphate removal from a synthetic feed phosphate wastewater in a 
batch sorption process. The characteristics and isotherms of the sorption process were examined and reported.

\section{Materials and Methods}

\subsection{Preparation of Gastropod Shell Powder}

The Gastropod (A. achatina) shell used was obtained from an open market in Ondo State, Nigeria. The shell was washed with tap water and rinsed thoroughly with deionized water, dried in the oven at $90^{\circ} \mathrm{C}$ for $24 \mathrm{~h}$ and crushed using a laboratory ceramic mortar and pestle. The crushed shell was made into powder and sieved with mesh of known size.

\subsection{Synthesis of CaCr LDH Samples}

The LDH samples were prepared via the co-precipitation method as described by [9], using gastropod shell powder as the source of $\mathrm{Ca}\left(\mathrm{M}^{2+}\right)$ and $\mathrm{CrCl}_{3}$ as the source of $\mathrm{Cr}\left(\mathrm{M}^{3+}\right)$, at varying molar ratios $\left(\mathrm{M}^{2+} / \mathrm{M}^{3+}\right)$ of $1: 1,2: 1$ and $4: 1 . \mathrm{CaCl}_{2}$ solution was prepared by dissolving $50 \mathrm{~g}$ of gastropod shell powder in $350 \mathrm{ml}$ of dilute $\mathrm{HCl}$. The mixture was vigorously stirred and left to stand for $24 \mathrm{~h}$. $500 \mathrm{ml}$ of the $\mathrm{CaCl}_{2}$ solution was added to $47.62 \mathrm{~g}, 23.81 \mathrm{~g}$ and $11.90 \mathrm{~g}$ of $\mathrm{CrCl}_{3}$ giving a Ca: Cr solution mixture of mass ratios of $1: 1,2: 1$ and $4: 1$, respectively. The mixture was thoroughly stirred and $2 \mathrm{M}$ $\mathrm{NaOH} / \mathrm{Na}_{2} \mathrm{CO}_{3}$ solution was added drop-wise as precipitant. The precipitate formed was allowed to gelate in the mother liquor for $24 \mathrm{~h}$ at room temperature and washed with deionized water repeatedly. The precipitate was collected and dried to constant weight at $80^{\circ} \mathrm{C}$. The synthesized $\mathrm{LDH}$ samples were labeled $\mathrm{LDH}_{1}, \mathrm{LDH}_{2}$ and $\mathrm{LDH}_{4}$, the subscript denotes the $\mathrm{Ca}$ : $\mathrm{Cr}$ mass ratio used in the synthesis.

\subsection{Characterization of Synthesised CaCr LDH Samples}

The crystallinity and mineralogical analysis of the samples were recorded on a Rigaku (RINT 2100) X-ray diffractometer (XRD) with a graphite monochromator and a Ni-filtered $\mathrm{Cu} K \alpha$ radiation $(\lambda=0.15406 \mathrm{~nm})$. The measurement was run in the $2 \theta$ range from $2^{\circ}$ to $90^{\circ}$ at a step size of 0.02 and counting time of $1 \mathrm{~s}$ per step. The divergence slit size was $0.0573^{\circ}$, while the operating voltage and current were $45 \mathrm{kV}$ and $40 \mathrm{~mA}$, respectively. The data were processed using PAN analytical X'PERT software. The surface physiognomies and elemental composition were analyzed using a Scanning Electron Microscope (JEOL: JSM - 6301F) equipped with Energy Dispersive analysis of X-ray (Oxford INCA 400, Germany). The samples were coated with gold before analysis with the aid of a sputter coater. Operating conditions were: accelerating voltage $=15 \mathrm{kV}$, current $=12 \mathrm{~mA}$, working distance $=10 \mathrm{~mm}$ and magnification up to $100,000 \mathrm{x}$. The surface functional groups were determined using Fourier Transform Infrared (FTIR) spectrophotometer (Thermo Scientific, USA). Sample pellet was prepared by mixing $1 \mathrm{mg}$ of the sample powder with 250 $\mathrm{mg}$ of $\mathrm{KBr}$ (AR grade) and pressing at 10,000 psi using a hydraulic press. The measurement covered the range from 500 to $4000 \mathrm{~cm}^{-1}$ with a resolution of $4 \mathrm{~cm}^{-1}$

\subsection{Adsorption Isotherm Study}

Phosphate adsorption isotherms were carried out using solid samples of $\mathrm{CaCr} \mathrm{LDH}$ in a batch system at room temperature. A stock solution $(300 \mathrm{mg} / \mathrm{l})$ of synthetic feed phosphate wastewater was prepared by dissolving $0.43 \mathrm{~g}$ of $\mathrm{KH}_{2} \mathrm{PO}_{4}$ (AR grade) in $1000 \mathrm{ml}$ distilled water and working solutions of varying concentrations (25-300 mg/l) were prepared from the stock by serial dilution. The equilibrium isotherm study of the process was evaluated by contacting 50 $\mathrm{ml}$ of phosphate solution of concentration $(25-300 \mathrm{mg} / \mathrm{l})$ with $0.1 \mathrm{~g}$ of the sample and agitated at $200 \mathrm{rpm}$ on a thermostatic shaker. After equilibration, suspensions were withdrawn using a syringe, centrifuged at $5000 \mathrm{~g}$ for $10 \mathrm{~min}$, filtered through a $0.22 \mu \mathrm{m}$ glass fiber filter. Residual phosphate in the supernatant was analyzed by the molybdenum-blue ascorbic acid method using a UV-VIS spectrophotometer at $801 \mathrm{~nm}$. The amount of phosphate sorbed per unit mass of the adsorbent (in $\mathrm{mg} / \mathrm{g}$ ) was calculated by using equations:

$$
\begin{gathered}
q_{e}=\frac{c_{o-c_{e}}}{m} \times v \\
R(\%)=100 \times \frac{C_{o-c_{e}}}{C_{0}}
\end{gathered}
$$

Where, $q_{e}=$ amount of $\mathrm{PO}_{4}{ }^{3-}$ sorbed per gramme of LDH $(\mathrm{mg} / \mathrm{g}), v=$ volume of $\mathrm{PO}_{4}{ }^{3-}$ solution $\left(\mathrm{dm}^{3}\right), m=$ mass of $\mathrm{LDH}(\mathrm{mg}), c_{o}=$ initial concentration of $\mathrm{PO}_{4}^{3-}$ in $\mathrm{mg} / \mathrm{l}, c_{e}=$ final residual $\mathrm{PO}_{4}{ }^{3-}$ concentration $(\mathrm{mg} / \mathrm{l})$. The phosphate laden residue obtained after phosphate uptake was washed with deionized water and dried in a desiccator for further analysis. The kinetics of the adsorption process and studies of process variables $(\mathrm{pH}$, presence of co-existing ions and organic load) shall be reported in a forth-coming paper.

\section{Results and Discussion}

\subsection{Characterisation of Synthesised LDH Samples}

The XRD patterns of the prepared LDHs in Figures 1-3 shows diffract graph of hydrocalumite- like materials. Sharp and intense symmetric peaks at low $2 \theta$ values and relatively less intense and symmetric basal reflections at higher $2 \theta$ values, characteristics of LDH-materials indicates the presence of Ca-Cr LDHs in the prepared materials [10-11]. Notably, the diffract graph of LDH1 sample differs from that of LDH2 and LDH4 samples in peak positions, intensities and basal lattice positions. Major diffractions peaks, d003 and $\mathrm{d} 006$ were reflected at $2 \theta$ values of $10.60^{\circ}$ and $23.03^{\circ}$ with d-spacings of $8.34 \AA$ and $3.86 \AA$, respectively for LDH2 sample, while for LDH4 sample these peaks were reflected at $10.86^{\circ}$ and $22.95^{\circ}$ with d- spacing of $8.15 \AA$ and $3.87 \AA$, respectively. These peaks were notably absent in the diffract graph of LDH1 sample. Other major characteristics reflections of hydrocalumite - like materials shown by $\mathrm{LDH}_{2}$ sample were peaks of $d_{009}$ and $d_{015}$ reflected at $2 \theta$ values of $35.88^{\circ}$ and $39.27^{\circ}$ with the d-spacing $2.50 \AA$ and $2.29 \AA$, 
respectively. $\mathrm{LDH}_{4}$ sample reflected other major peaks, $\mathrm{d}_{009}$, $\mathrm{d}_{015}$ and $\mathrm{d}_{110}$ at $2 \theta$ values of $35.81^{\circ}, 39.24^{\circ}$ and $62.48^{\circ}$ with the d-spacing of $2.52 \AA$, 2.29 and 1.48, respectively. Furthermore, the patterns of the sharpness and intensity of the peaks indicated an increase in the crystallinity of the samples with increase in the $\mathrm{Ca} / \mathrm{Cr}$ ratio from $\mathrm{LDH}_{1}$ to $\mathrm{LDH}_{4}$ (Figures 1-3) [6, 12]. Uncharacteristic LDH peaks observed in the diffractogram were attributed to the presence of impurities in the biogenic precursor. FTIR spectrum of the samples (Figures 4-6) is typical of hydrocalumite materials which are characterized by broad adsorption bands around $3450-3520 \mathrm{~cm}^{-1}$ attributed to $v_{\mathrm{OH}}$ stretching vibration of brucite- like layers [5].

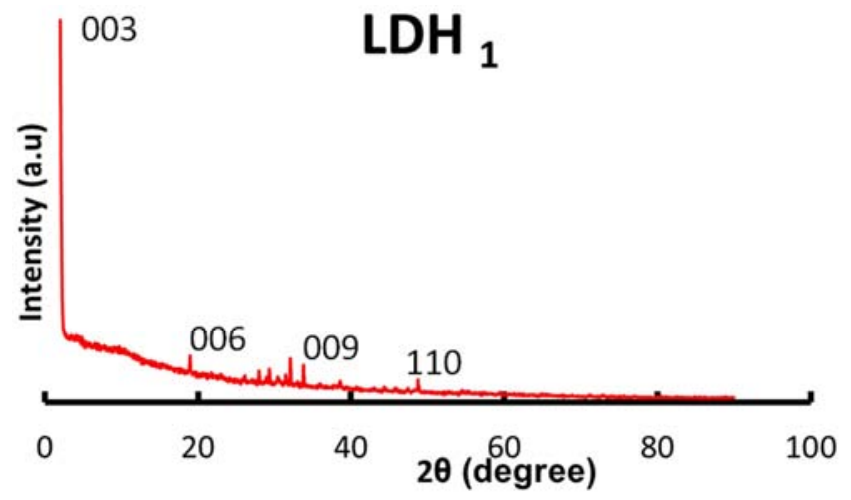

Figure 1. XRD pattern of $L D H_{1}$.

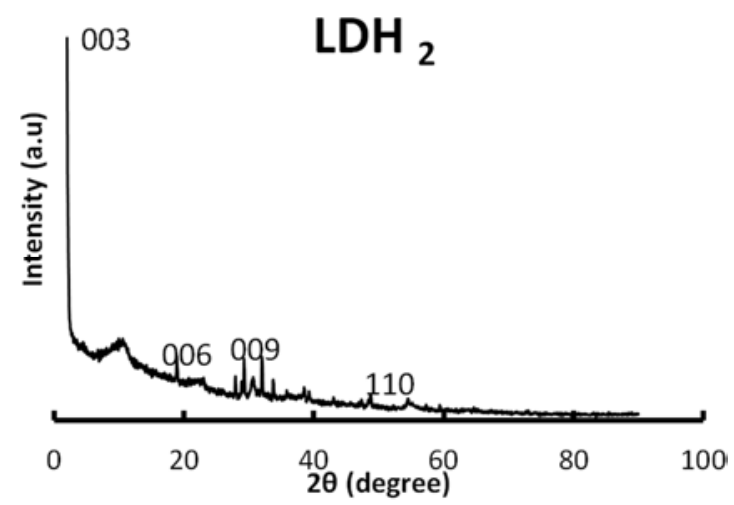

Figure 2. XRD pattern of $\mathrm{LDH}_{2}$.

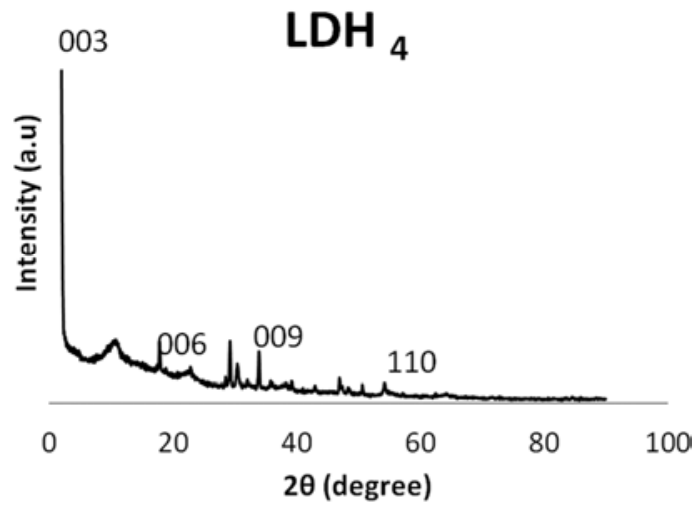

Figure 3. XRD pattern of $\mathrm{LDH}_{4}$.

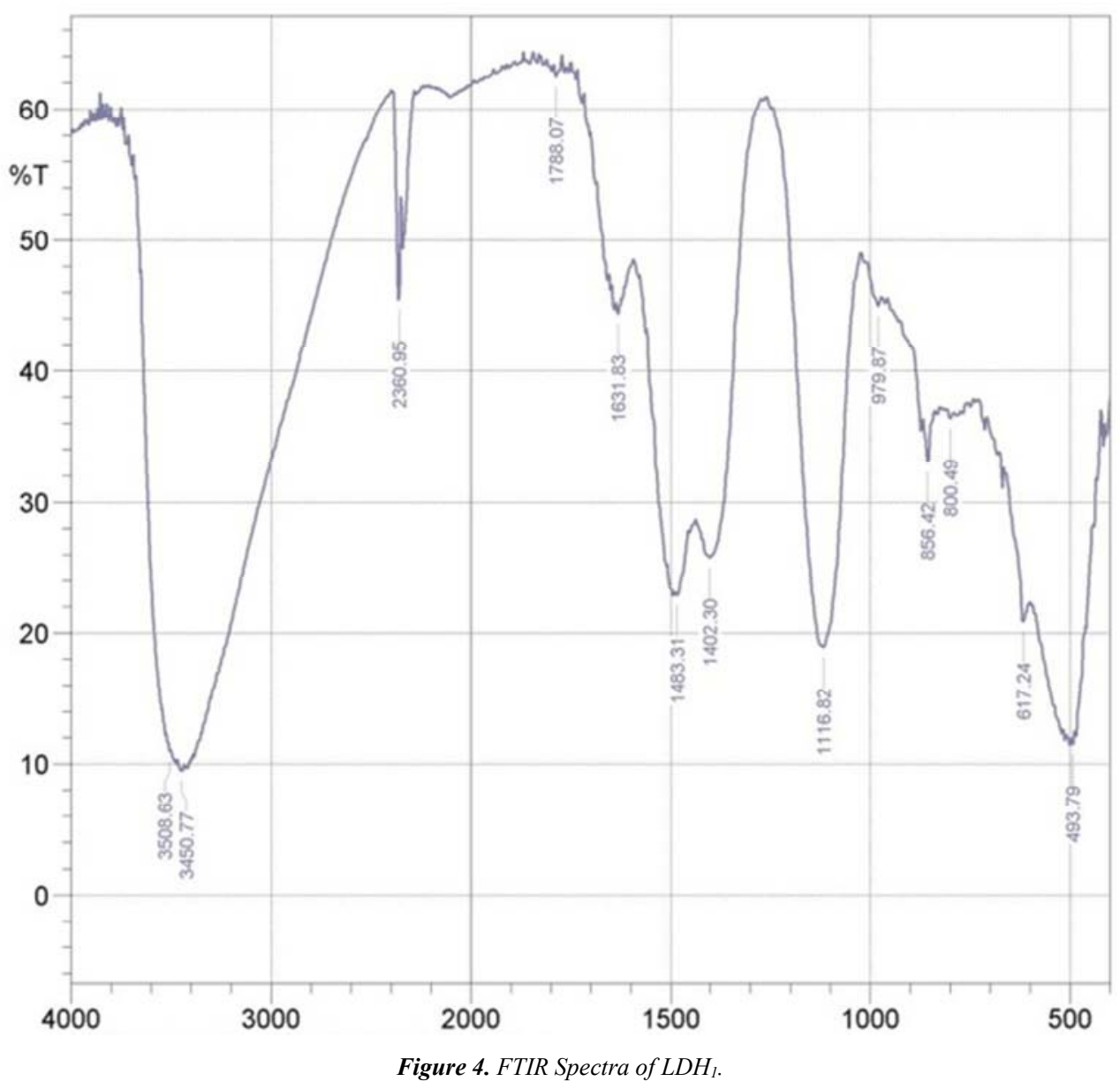




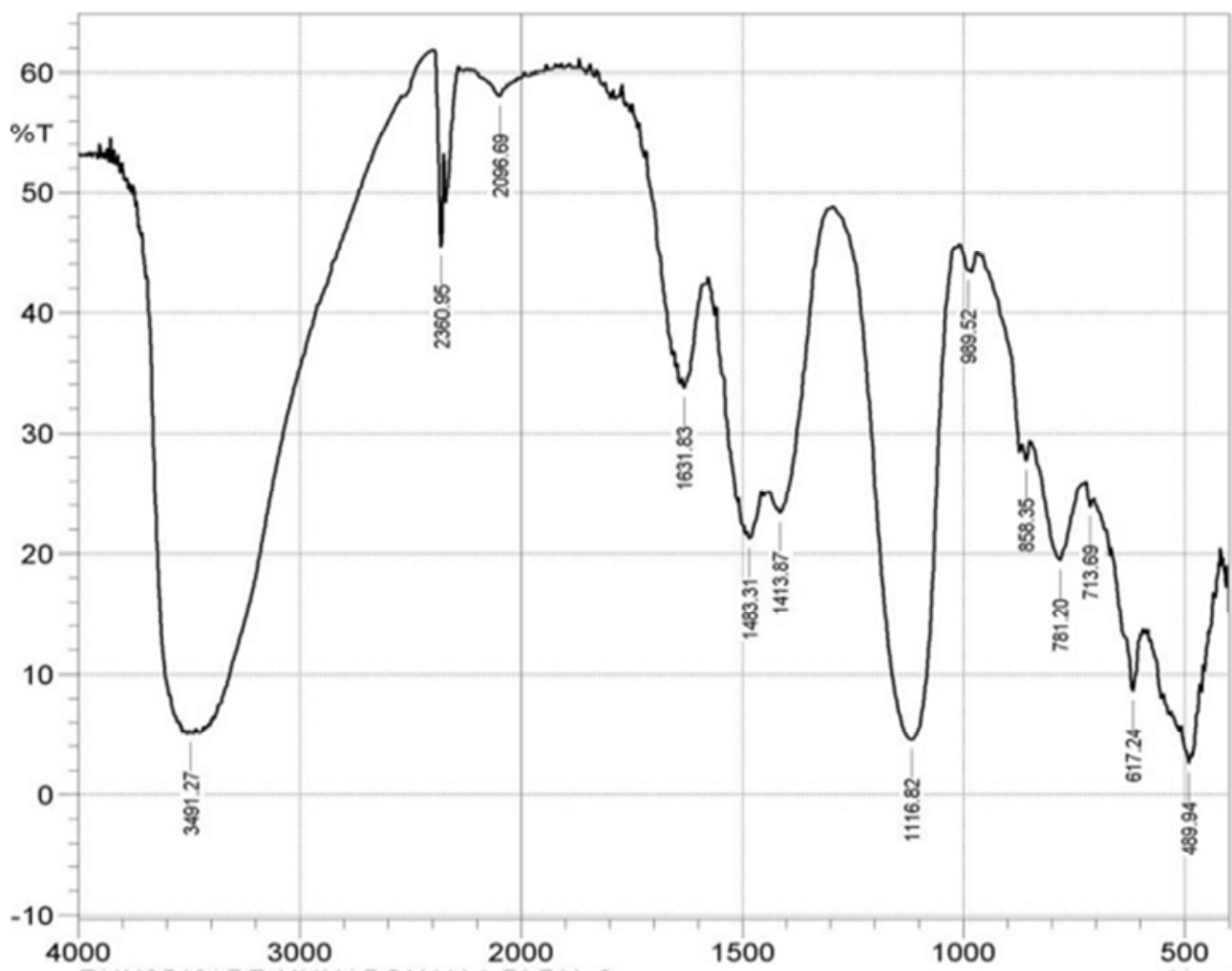

Figure 5. FTIR Spectra of $\mathrm{LDH}_{2}$.

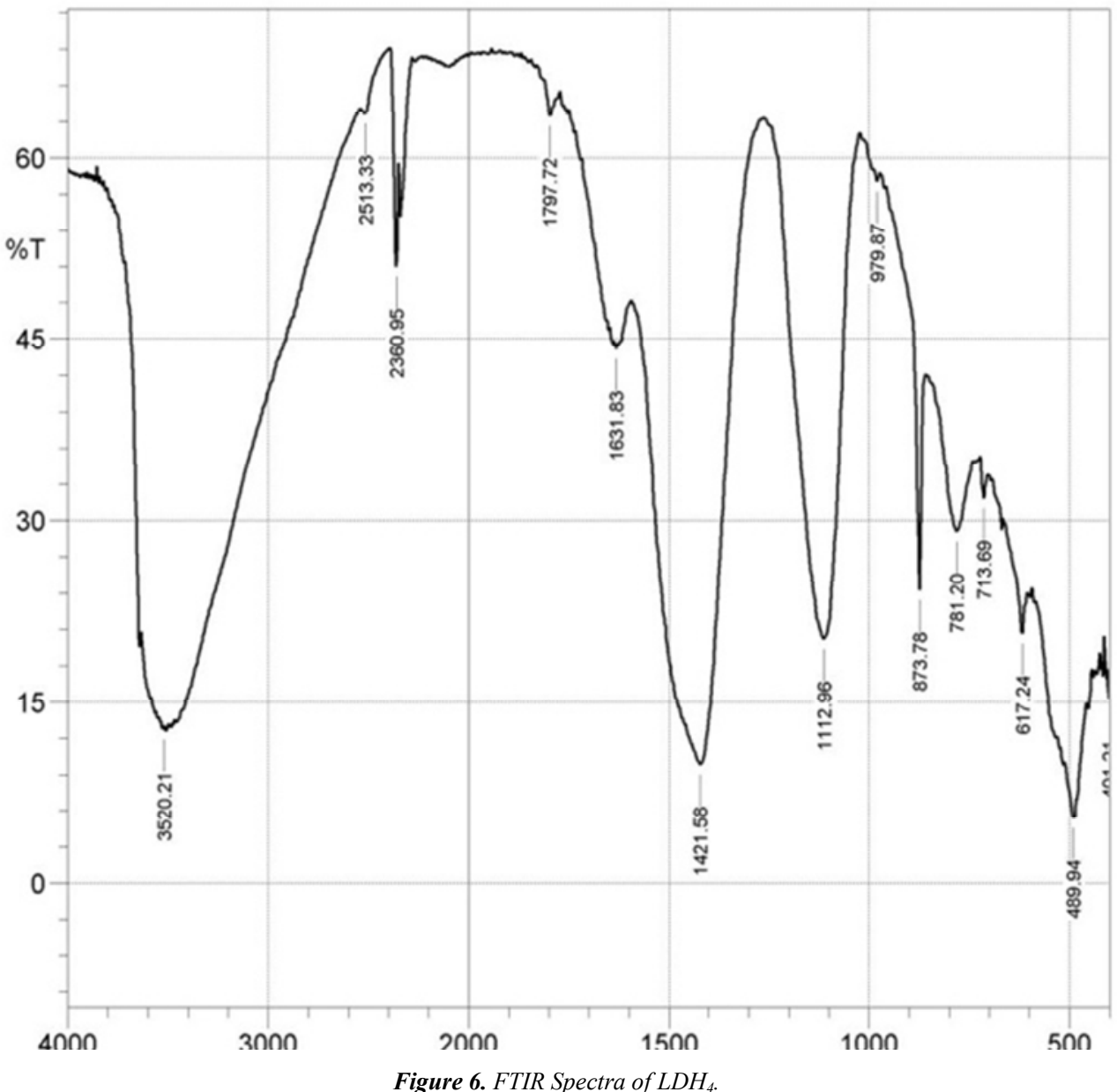


The bending vibration of the interlayer water $\delta_{\mathrm{H}-\mathrm{OH}}$ was found at $1631 \mathrm{~cm}^{-1}$. The bands at $1413 \mathrm{~cm}^{-1}, 1116 \mathrm{~cm}^{-1}$, and $617 \mathrm{~cm}^{-1}$ were attributed to $\mathrm{CO}_{3}{ }^{2-}$, due to asymmetric stretching, symmetric stretching and bending modes, respectively [3, 13-14]. The weak band around $750-800 \mathrm{~cm}^{-1}$ was attributed to $\mathrm{M}-\mathrm{O}-\mathrm{M}$ vibration in the brucite-like layer while the bands around $480-500 \mathrm{~cm}^{-1}$ corresponded to $\mathrm{M}-\mathrm{OH}$ stretching and bending vibrations. Characteristic IR band of chromate was recorded at $856-880 \mathrm{~cm}^{-1}$. SEM / EDX techniques were utilized to determine the LDHs surficial morphology and elemental chemical composition as a function of preparation adopted for the materials. SEM images of the samples presented in Figures 7-9 showed that the samples were composed of agglomerates of tiny hexagonal crystals fused together. The results obtained via EDX analysis indicated the presence of $\mathrm{Ca}, \mathrm{Cr}, \mathrm{Cl}$ and $\mathrm{O}$ in all the samples (Figures 10-12). Furthermore, the results showed that the $\mathrm{M}^{2+} / \mathrm{M}^{3+}$ molar ratios of the samples are smaller than that of the starting solutions (Table 1) which is an indication of incomplete reaction between $\mathrm{Ca}^{2+}$ and $\mathrm{Cr}^{3+}$.

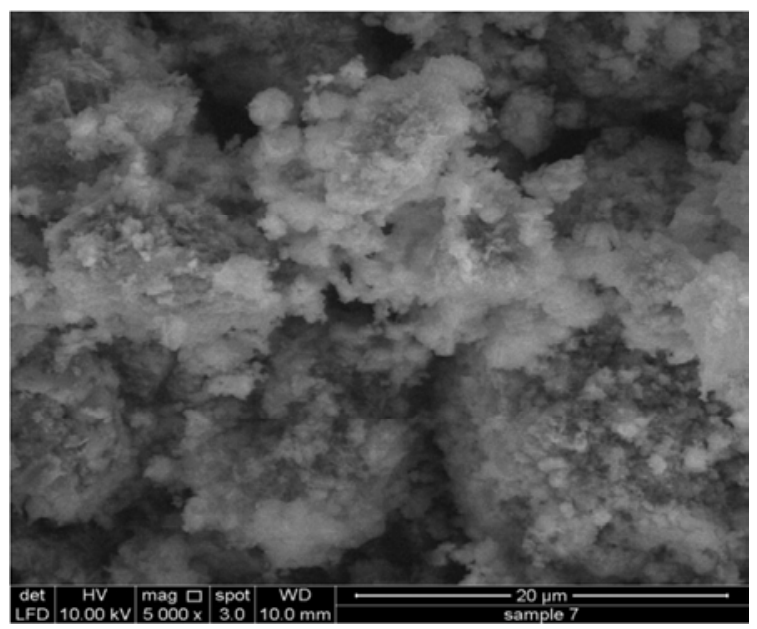

Figure 7. SEM images of $L H D_{l}$.

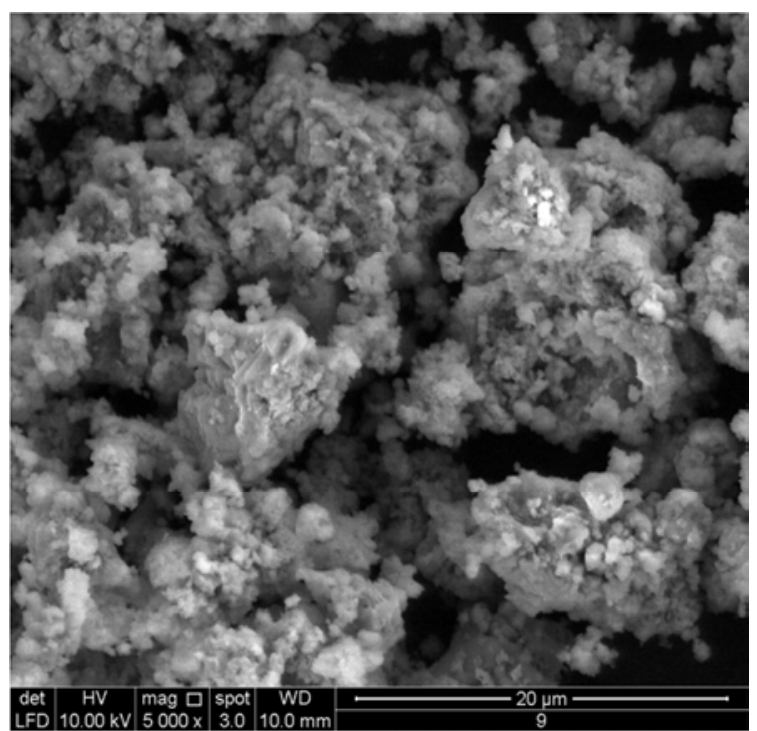

Figure 8. SEM images of $\mathrm{LHD}_{2}$

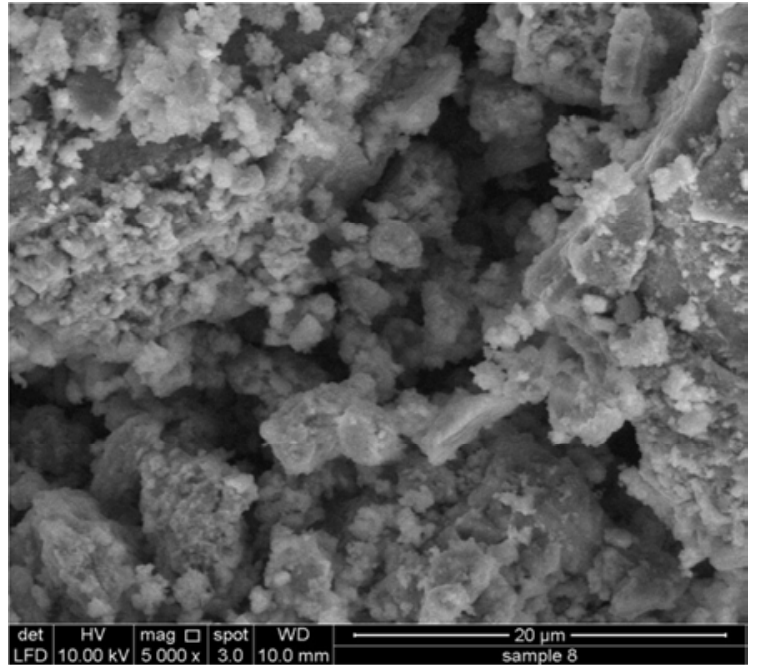

Figure 9. SEM images of $\mathrm{LHD}_{4}$.

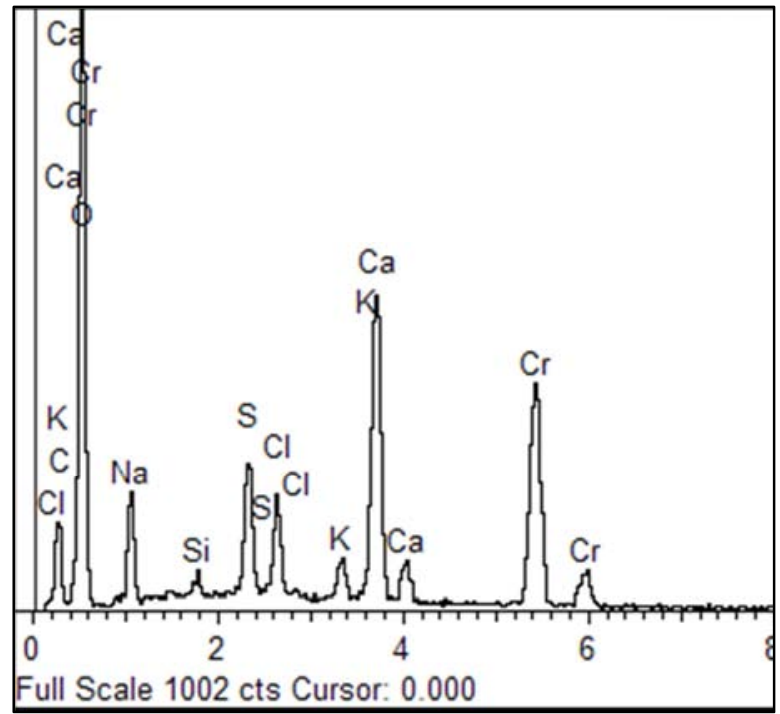

Figure 10. EDX spectra of $L D H_{l}$.

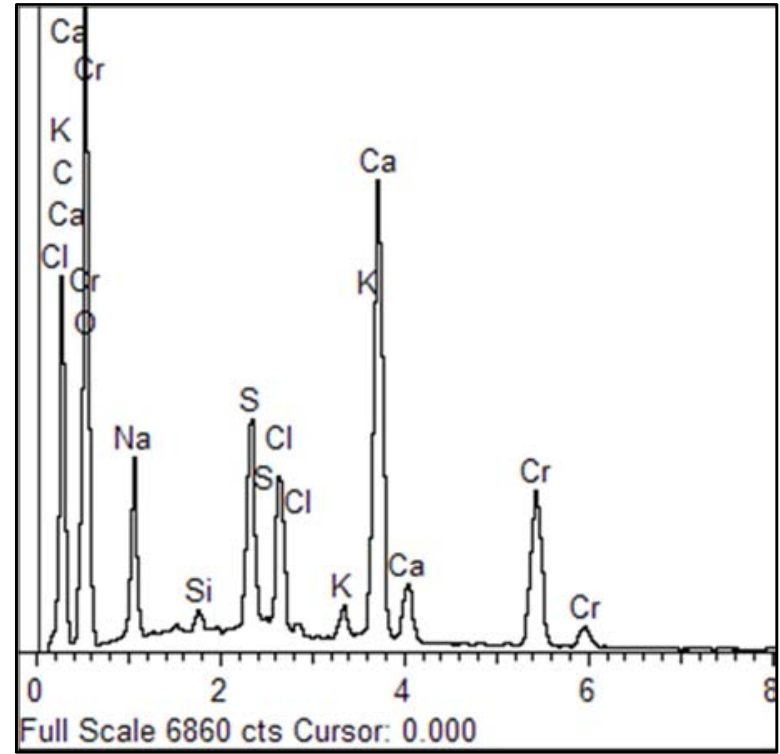

Figure 11. EDX spectra of $\mathrm{LDH}_{2}$ 


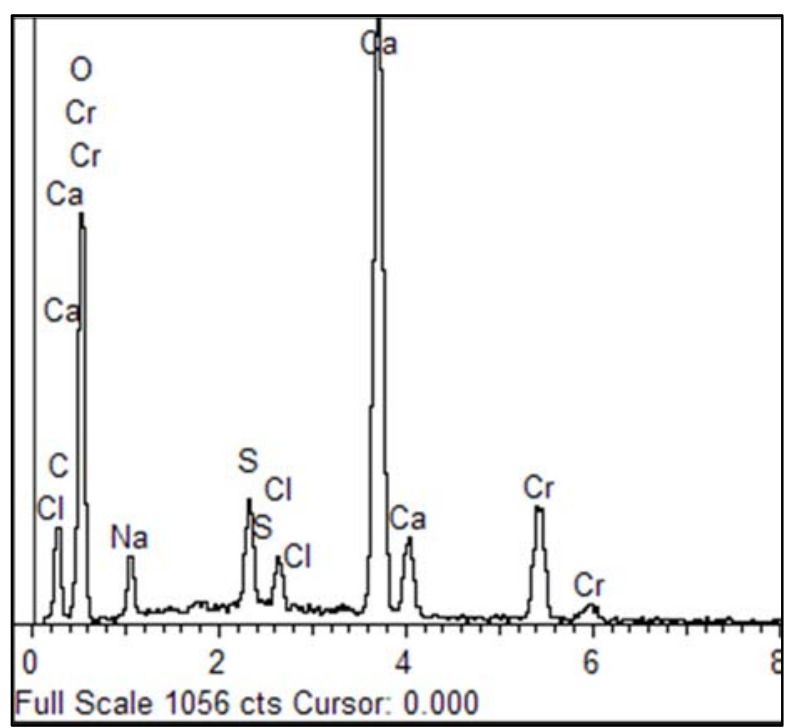

Figure 12. EDX spectra of $\mathrm{LDH}_{4}$.

Table 1. Molar ratios of Synthesised LDHs Samples by EDX Analysis.

\begin{tabular}{lllll}
\hline Samples & $\begin{array}{l}\mathbf{C a}^{\mathbf{2 +}} \\
(\mathbf{\%})\end{array}$ & $\begin{array}{l}\mathbf{C r}^{3+} \\
(\mathbf{\%})\end{array}$ & $\begin{array}{l}\text { Solid Molar } \\
\text { Ratio }\left(\mathbf{M}^{++} / \mathbf{M}^{3+}\right)\end{array}$ & $\begin{array}{l}\text { Solution Molar } \\
\text { Ratio }\left(\mathbf{M}^{\mathbf{2 +}} / \mathbf{M}^{3+}\right)\end{array}$ \\
\hline $\mathrm{LDH}_{1}$ & 5.84 & 6.74 & 0.87 & $1: 1$ \\
$\mathrm{LDH}_{2}$ & 4.84 & 2.63 & 1.08 & $1: 2$ \\
$\mathrm{LDH}_{4}$ & 10.92 & 3.38 & 3.23 & $1: 4$ \\
\hline
\end{tabular}

\subsection{Adsorption Studies of Phosphate Removal by LDH Samples}

\subsubsection{Effect of CaCr Molar Ratio}

In order to assess the effect of molar ratio $\left(\mathrm{M}^{2+}: \mathrm{M}^{3+}\right)$ on phosphate removal, the prepared LDHs of varying molar ratios (1:1, 2:1, 4:1) were subjected to the adsorption assays. It was observed that the amount of phosphate removed by the samples increased with increasing molar ratio. While about $90 \%$ and $95 \%$ removal was observed with $\mathrm{LDH}_{1}$ and $\mathrm{LDH}_{2}$ samples, respectively, about $98 \%$ removal occurred with
$\mathrm{LDH}_{4}$ sample. The partial substitution of $\mathrm{Cr}^{3+}$ for $\mathrm{Ca}^{2+}$ causes an increase in the net positive charge as a result of differences in the ionic radius of the cations [15]. This causes a phase change leading to increase in its adsorption capacity. The sorption capacity of the LDHs increases with increasing $\mathrm{Ca}^{2+}$ and reduced $\mathrm{Cr}^{3+}$ contents. Substances with high $\mathrm{Ca}$ contents have shown to have high affinity for phosphate [16]. The marginal similarities in the amount of phosphate removed $(90,95,98 \%)$ by the LDHs suggest that the type of metal (especially divalent) influences the sorption capacity of the LDHs more than net positive charge. The $\mathrm{Ca}-\mathrm{Cr}$ of molar ratio $2\left(\mathrm{LDH}_{2}\right)$ appeared optimal for phosphate uptake from aqua system and was used for subsequent studies.

\subsubsection{Effect of Initial Phosphate Concentration}

The effect of initial phosphate concentration on phosphate uptake by $\mathrm{LDH}_{2}$ was assessed at varying initial phosphate concentrations $(25-300 \mathrm{mgP} / \mathrm{l})$, by contacting $0.1 \mathrm{~g}$ of $\mathrm{LDH}$ with $50 \mathrm{ml}$ of $40 \mathrm{mgP} / 1$ phosphate solution, $\mathrm{pH}$ of 5.5, for $2 \mathrm{hr}$. The amount of phosphate removed by the adsorbent increased with increase in contact time for all initial phosphate concentrations studied, with a phosphate uptake of $>98 \%$ within the first 5 mins of contact, after which equilibrium gradually sets in (Figure 13). The initial rapid uptake was ascribed to the difference in concentration between the solute concentration in solution and that at the surface of the adsorbent present at the commencement of the sorption process. Furthermore, the result (Figure 13) revealed that phosphate uptake increases with increase in initial phosphate concentration. The magnitude of phosphate removed by the adsorbent varied with the initial phosphate concentrations. The increased removal observed at higher initial concentration is as a result of the increase in the driving force of overcoming all mass transfer resistance between adsorbent moieties and the adsorbate [11, 17]. Consequently, an increase in the initial phosphate concentration led to increase in the amount of phosphate removed per gram of the $\mathrm{LDH}_{2}$.

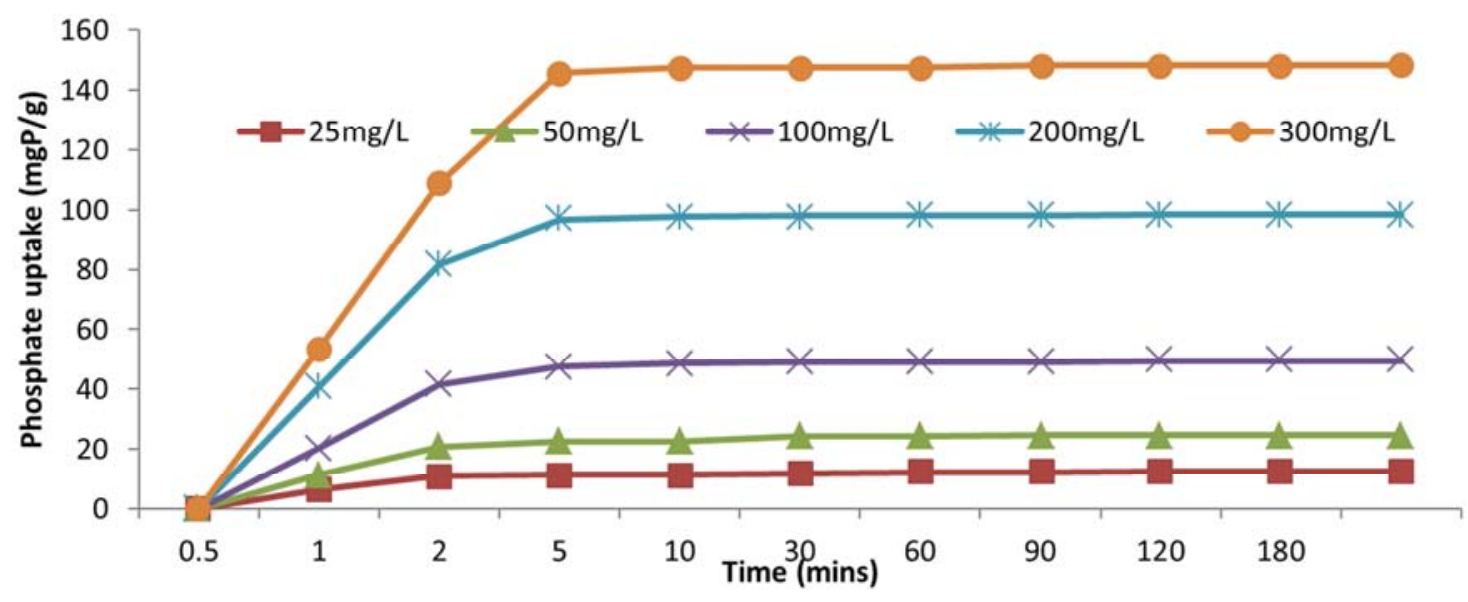

Figure 13. Phosphate uptake by $\mathrm{LDH}_{2}$ as a function of initial phosphate concentration.

\subsubsection{Adsorption Equilibrium Isotherm Studies}

In adsorption process, equilibrium is established when the concentration of the adsorbate in the bulk solution is in dynamic balance with that at the interface of the adsorbent. Adsorption isotherms are mathematical models characterized by certain constants whose values express the surface properties and affinity of the adsorbents for the adsorbates 
[18-19]. The adsorption equilibrium experimental data of phosphate removal by $\mathrm{LDH}_{2}$ from aqueous solution were modeled using adsorption isotherms of Langmuir, Freundlich, Temkin and Harkins-Jura. The Langmuir isotherm model assumes a monolayer adsorption on specific homogeneous sites within the adsorbent and that there is no significant interaction among the adsorbed species. The Freundlich isotherm model regarded as an empirical equation, indicates non-uniformity of the adsorbent surface, is also used to describe chemisorption on a heterogeneous surface. The Temkin isotherm model takes into account the interactions between adsorbent and adsorbate and is based on the assumption that the free energy of adsorption is simply a function of surface coverage. Halsey isotherm model is be used to evaluate the multilayer adsorption system for adsorption at a relatively large distance from the surface. The non- linear expression of these models is given as:

$$
\text { Langmuir: } q e=\frac{q_{m} b c_{e}}{1+b c_{e}}
$$

$$
\begin{aligned}
& \text { Freundlich: } q_{e}=k_{f} c_{e}^{1 / n} \\
& \text { Temkin: } q_{e}=B_{T} \ln A C_{e} \\
& \text { Halsey } \mathrm{q}_{\mathrm{e}}=e^{\frac{\ln k-\ln c_{e}}{n}}
\end{aligned}
$$

Where, $c e$ is the concentration of the phosphate at equilibrium $(\mathrm{mg} / \mathrm{L}), q e$ is the amount of phosphate sorbed at equilibrium per unit mass of $\mathrm{LDH}_{2}(\mathrm{mg} / \mathrm{g}), q_{m}$ is the monolayer sorption capacity at equilibrium $(\mathrm{mg} / \mathrm{g})$ and $b$ is the Langmuir constant $\left(\mathrm{dm}^{3} / \mathrm{g}\right)$. The constant, $k_{f}$, is the Freundlich constant and $n$ is the sorption intensity, $B_{T}(\mathrm{~J} / \mathrm{mol})$ corresponds to the heat of adsorption, is the Temkin isotherm constant and $A(\mathrm{l} / \mathrm{g})$ is the equilibrium binding constant, corresponding to the maximum binding energy. Details of the values of the isotherm parameters obtained from the plots (Figure 14) of the experimental data of adsorption equilibrium study to the aforementioned isotherm equations are presented in Table 2.
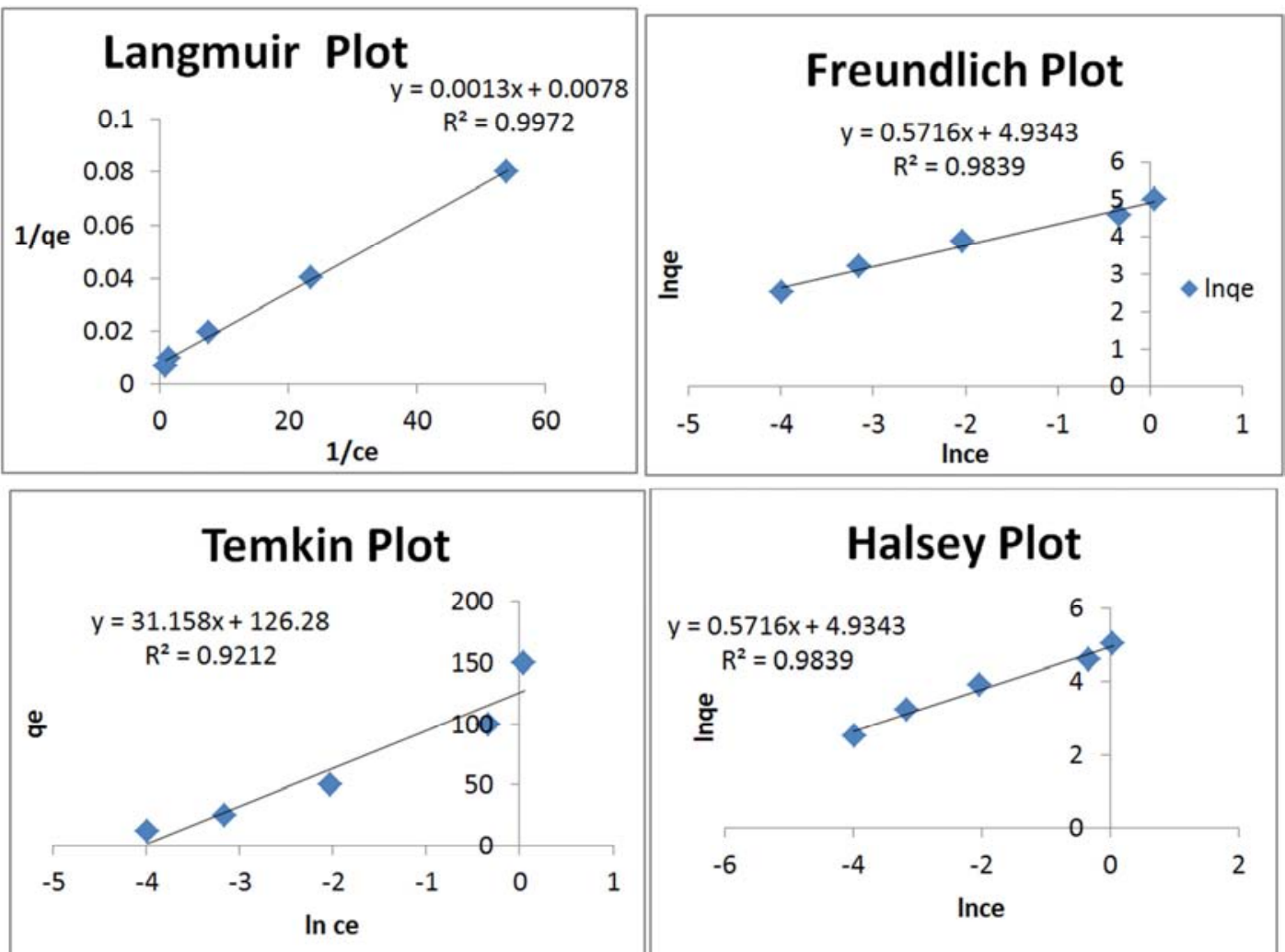

\section{Halsey Plot}

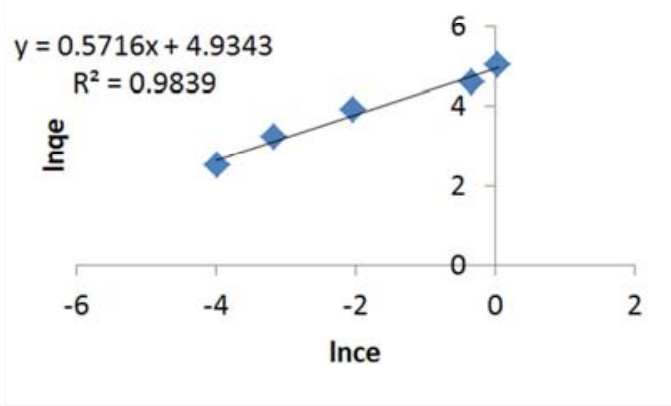

Figure 14. Equilibrium Isotherms Models Plots for the Removal of Phosphates by $\mathrm{LDH}_{2}$.

The Langmuir monolayer adsorption capacity $\left(q_{m}\right)$ of $\mathrm{LDH}_{2}$ for phosphate was $142.86 \mathrm{mg} / \mathrm{g}$. The magnitude of $b(0.634$ $\mathrm{L} / \mathrm{mg}$ ) showed high binding energy of phosphate sorption on the $\mathrm{LDH}_{2}$. The low value of the Freundlich constant, $n$, (1.75), is an indication of a favourable process, while the high value of $K_{f}(138.93 \mathrm{mg} / \mathrm{g})$ is a pointer to the high affinity of the $\mathrm{LDH}_{2}$ samples for phosphates. Values of the Temkin parameters obtained were high $\left(B_{T}=31.15 \mathrm{~kJ} / \mathrm{mol}, A=4.051\right.$ $\mathrm{L} / \mathrm{g}$ ), indication of high sorption energy and maximum binding energy, respectively. From the plots, the adsorption curves relating the solid and liquid phase concentration of phosphate at equilibrium to the Langmuir, Freundlich, Temkin and Halsey isotherm equations are given as:

$$
\begin{gathered}
\text { Langmuir: } q_{e}=\frac{141.86 c_{e}}{1+0.634 c_{e}} \\
\text { Freundlich: } q_{e}=138.93 C_{e}^{0.571} \\
\text { Temkin } q_{e}=31.15 \ln 4.05 C_{e}
\end{gathered}
$$




$$
\text { Halsey } q_{e}=e \frac{\ln 138.93-\ln c_{e}}{1.7513}
$$

Evaluation of the fittings of the isotherm models to the experimental data was tested using the linear coefficient of determination $\left(\mathrm{R}^{2}\right)$ and the non-linear chi-square $\left(x^{2}\right)$. The linear coefficient of determination, $\left(\mathrm{R}^{2}\right)$ indicates the percentage of variability in the dependent variable that has been explained by the regression line. The value of $\mathrm{R}^{2}$ varies between zero and one. A value of one indicates that $100 \%$ of the variation of the amount of phosphate sorbed has been explained by the regression line. The linear coefficient of determination was estimated using equation:

$$
r^{2}=\frac{S_{x y}^{2}}{S_{x x} S_{y y}}
$$

Where $S_{x x}$ is the sum of square of $x, S_{y y}$ is the sum of squares of $y$ and $S_{x y}$ is the sum of squares of $x$ and $y$. Furthermore, the non- linear chi-square test is a statistical tool used to determine the best fit of an adsorption system. It is obtained by judging the sum squares differences between the experimental and the calculated data with each squared difference being divided by its corresponding value (calculated from the models). Small value of $x^{2}$ is an indication of the suitability of the model to the experimental data, while large number represents variation of the model to the experimental data. Mathematically, it is calculated from the equation:

$$
\chi^{2}=\sum \frac{\left(q_{e}-q_{e, m}\right)^{2}}{q_{e, m}}
$$

The values of $\mathrm{R}^{2}$ and $\chi^{2}$ obtained for the isotherm models from their fittings to the experimental data are presented in Tables 2. Comparatively, the Langmuir isotherm model yielded a better fit than the other models with a very high $\mathrm{R}^{2}$ value (0.997) and negligible low chi- square value (0.0423). Consequent upon the equilibrium isotherm studies, it could be deduced that the sorption of phosphate by $\mathrm{LDH}_{2}$ was favourable as indicated by high adsorption intensity values ( $n$ and b) between phosphate and $\mathrm{LDH} 2$ which implies a strong bond. Furthermore, sorption of phosphate occurred on monolayer surface of the $\mathrm{LDH}_{2}$ sample.

Table 2. Calculated Equilibrium Constants for Phosphate adsorption on $\mathrm{LDH}_{2}$.

\begin{tabular}{lllll}
\hline Langmuir & Freundlich & Temkin & Halsey & Dubinin -Radushkevich \\
\hline $\mathrm{q}_{\mathrm{m}}(\mathrm{mg} / \mathrm{g}): 142.86$ & $\mathrm{~K}_{\mathrm{f}}(\mathrm{mg} / \mathrm{g}): 138.93$ & $\mathrm{~B}_{T}(\mathrm{~kJ} / \mathrm{mol}): 31.15$ & $\mathrm{~K}_{\mathrm{H}}(\mathrm{mg} / \mathrm{l}): 138.93$ & $\mathrm{qm}(\mathrm{mol} / \mathrm{g}): 76.172$ \\
$b(\mathrm{~L} / \mathrm{mg}): 0.634$ & $1 / \mathrm{n}: 0.571$ & $\mathrm{~A}(\mathrm{~L} / \mathrm{g}): 4.05$ & $\mathrm{n}: 0.571$ & $\mathrm{E}(\mathrm{kJ} / \mathrm{mol}): 15.623$ \\
$\mathrm{R}^{2}: 0.997$ & $\mathrm{R}^{2}: 0.983$ & $\mathrm{R}^{2}: 0.921$ & $\mathrm{R}^{2}: 0.983$ & $\mathrm{~K}_{\mathrm{DR}}\left(\mathrm{mol} / \mathrm{l}^{2} / \mathrm{kJ}^{2}\right): 0.002$ \\
$\chi^{2}: 0.0423$ & $\chi^{2} 0.1854$ & $\chi^{2}: 2.5427$ & $\chi^{2}: 0.6120$ & $\chi^{2}: 2.7252 ; \mathrm{R}^{2}: 0.765$ \\
\hline
\end{tabular}

\subsubsection{Estimation of Energy of Sorption}

The energy of sorption process of phosphate on $\mathrm{LDH}_{2}$ was estimated by testing the experimental sorption data obtained from the equilibrium isotherm studies with the Dubinin Radushkevich (D-R) equation expressed as: lnqe $=$ lnqm $\mathrm{k} \varepsilon^{2}$ (14)

$$
\text { Where, } \varepsilon=R T\left(1+\frac{1}{c e}\right)
$$

And,

$$
E=\frac{1}{\sqrt{2 \mathrm{~K}}}
$$

Where, $q_{m}(\mathrm{~mol} / \mathrm{g})$ is the D-R constant representing the theoretical saturation capacity, $\varepsilon$ (polanyi potential) is calculated using Eqn. 15. The parameters $q_{m}$ and $k$, calculated from the intercept and slope of the plots of $\ln q_{e}$ against $E^{2}$ were $76.172 \mathrm{~mol} / \mathrm{g}$ and 0.002 , respectively (Table 3 ). Insight into the type of adsorption process as chemisorption or physisorption was determined by considering the value of the constant $\mathrm{E}$, the mean free energy of adsorption per molecule of the adsorbate when transferred to the surface of the solid from infinity in solution [20]. $\mathrm{K}$ is related to the mean adsorption energy $E(\mathrm{~kJ}$ $\mathrm{mol}^{-1}$ ) as shown in Eqn. 16. If the value of $E$ lies between 8 and $16 \mathrm{~kJ} / \mathrm{mol}$ the sorption process is considered as chemisorption, while values below $8 \mathrm{~kJ} / \mathrm{mol}$ indicate a physical adsorption process [21]. The $E(\mathrm{~kJ} / \mathrm{mol})$ value of the sorption process was found to be $15.623 \mathrm{~kJ} / \mathrm{mol}$. This value is relatively not in the range for physical adsorption, a pointer to the fact that chemisorption was the prevailing mechanism of interaction between phosphate and the $\mathrm{LDH}_{2}$ surface.

\subsubsection{Effect of Temperature and Evaluation of Thermodynamic Parameters}

The effect of temperature on the adsorption capacity of $\mathrm{LDH}_{2}$ was assessed at varying temperatures of 25,45 and $65^{\circ} \mathrm{C}$. Figure 15 displays the plot of amount of phosphate removed as a function of temperature. The amount of phosphate removed decreases with increase in temperature for all concentrations studied (50, 100, $200 \mathrm{mgP} / \mathrm{l})$. This suggests that lower temperatures are most suitable for phosphate sorption on $\mathrm{CaCr} \mathrm{LDH}$, indicating that the interaction between the adsorbate and adsorbent was exothermic in nature.

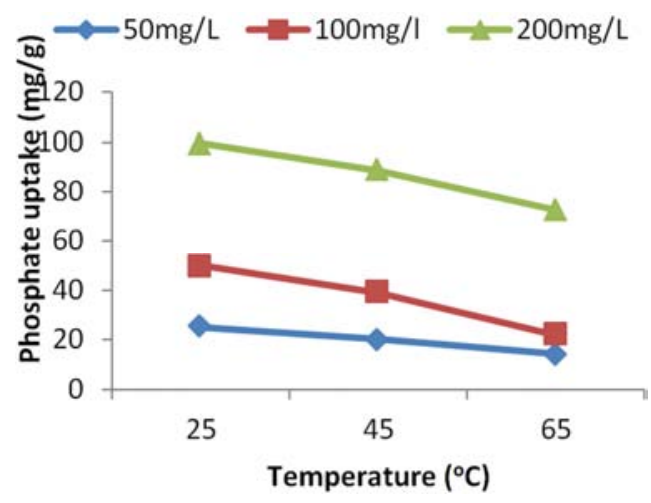

Figure 15. Phosphate Uptake as a Function of Temperature. 


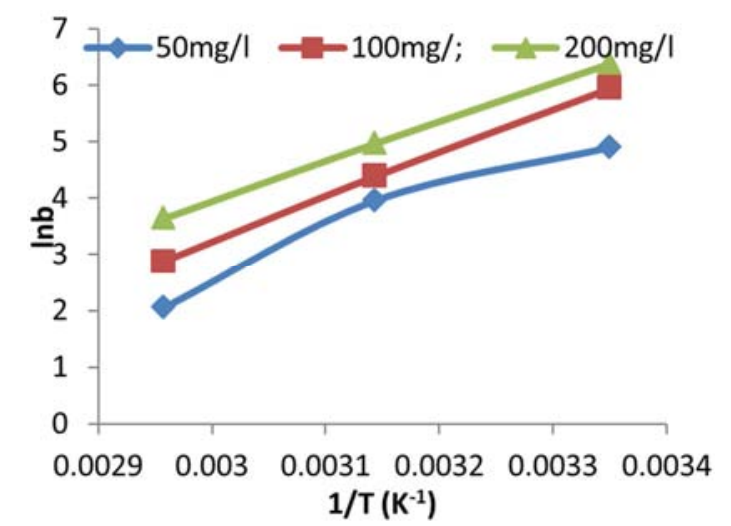

Figure 16. Plot of ln $b$ against 1/T for Thermodynamic Analysis.

Temperature dependence of adsorption process is associated with changes in thermodynamic parameters: Gibbs free energy $\left(\Delta \mathrm{G}^{0}\right)$, enthalpy $\left(\Delta \mathrm{H}^{0}\right)$ and entropy $\left(\Delta \mathrm{S}^{0}\right)$. The Gibbs free energy is the thermodynamic driven energy in chemical reactions, used to determine whether a reaction is spontaneous $(\Delta \mathrm{G}>0)$, at equilibrium $(\Delta \mathrm{G}=0)$ or not feasible $(\Delta \mathrm{G}<0)$. The value of Gibbs free energy is calculated by using the equation:

$$
\begin{gathered}
\Delta G^{O}=-R T \ln b \\
\ln b=\frac{\Delta S^{O}}{R}-\frac{\Delta H^{O}}{R T}
\end{gathered}
$$

Where, $\mathrm{R}$ is the universal gas constant, $\mathrm{T}$ is temperature (K) and $b$ is Langmuir constants. The results obtained for the thermodynamic analysis of the process indicated that the process is thermodynamically spontaneous with negative values obtained for Gibbs free energy $(\Delta G<0)$ and ranged between -12140 and -5760 (Table 3). The enthalpy $\left(\Delta \mathrm{H}^{\circ}\right)$ and entropy $\left(\Delta \mathrm{S}^{\mathrm{o}}\right)$ of the process were evaluated using Van't Hoff equation (18). Values of $\Delta \mathrm{H}^{\mathrm{o}}$ and $\Delta \mathrm{S}^{\mathrm{o}}$ calculated from the slope and intercept of the linear plots of $\ln b$ versus $1 / \mathrm{T}$ (Figure 16) is presented in Table 3. The negative values of $\Delta \mathrm{H}^{\mathrm{o}}$ indicated the exothermic nature of the sorption process, while the negative values of $\Delta S^{o}$ indicated decreased randomness at the solid / solution interface during the sorption of $\mathrm{PO}_{4}{ }^{3-}$ on $\mathrm{LDH}_{2}$.

\begin{tabular}{|c|c|c|c|c|c|c|c|c|c|}
\hline$T(K)$ & $50 \mathrm{mg} / \mathrm{l}$ & & & $100 \mathrm{mg} / \mathrm{l}$ & & & $200 \mathrm{mg} / \mathrm{l}$ & & \\
\hline & $\Delta G^{0}$ & $\Delta \boldsymbol{S}^{\boldsymbol{O}}$ & $\Delta \boldsymbol{H}^{O}$ & $\Delta G^{O}$ & $\Delta \boldsymbol{S}^{\boldsymbol{O}}$ & $\Delta \boldsymbol{H}^{\boldsymbol{O}}$ & $\Delta G^{o}$ & $\Delta \boldsymbol{S}^{o}$ & $\Delta \boldsymbol{H}^{\boldsymbol{O}}$ \\
\hline 298 & -12140 & & & -14716 & & & -15806 & & \\
\hline 318 & -10469 & -19.11 & -7222 & -11607 & -20.17 & -7801 & -12933 & -17.01 & -6987 \\
\hline 338 & -5760 & & & -8093 & & & -10229 & & \\
\hline
\end{tabular}

Table 3. Thermodynamic Parameters Changes of Phosphate Removal by $\mathrm{LDH}_{2}$ Samples.

\subsection{Characterisation of Phosphate - Laden LDH.}

Characterisation of the spent LDH samples studies gives an insight into the possible mechanisms of the sorption process which are used to elucidate the interaction between adsorbate and adsorbent for optimization of the operation parameters of an adsorption process. Several studies have opined that anions are adsorbed on LDHs by either anion exchange with the hydroxyl anions in the water solution, electrostatic interaction and/or formation of complex (outersphere / inner sphere) [14, 22]. SEM analysis revealed a change in the surface architecture of the spent LDH sample after phosphate sorption (Figure 17). Elemental composition of the spent LDH samples by EDX analysis provided a clear evidence of the sorption of phosphate on the surface of $\mathrm{P}$ laden $\mathrm{LDH}_{2}$ (Figure 18). Notably, the decrease in the amount of chloride and increase in phosphate content of the spent$\mathrm{LDH}_{2}$ sample indicated the possibility of anion exchange between chloride and phosphate ions during the sorption process (Table 4).

Table 4. Elemental composition in the $\mathrm{CaCr} \mathrm{LDH}_{2}$ before and after phosphate uptake.

\begin{tabular}{lll}
\hline Element & Before Uptake (\%) & After Uptake (\%) \\
\hline $\mathrm{C}$ & 24.91 & 23.33 \\
$\mathrm{O}$ & 45.50 & 42.68 \\
$\mathrm{Na}$ & 5.09 & 1.06 \\
$\mathrm{P}$ & 0 & 6.27 \\
$\mathrm{~S}$ & 3.47 & 1.07 \\
\hline
\end{tabular}

\begin{tabular}{lll}
\hline Element & Before Uptake (\%) & After Uptake (\%) \\
\hline $\mathrm{Cl}$ & 2.97 & 1.10 \\
$\mathrm{Ca}$ & 11.01 & 18.69 \\
$\mathrm{Cr}$ & 7.76 & 5.80 \\
$\mathrm{Total}$ & 100 & 100 \\
\hline
\end{tabular}

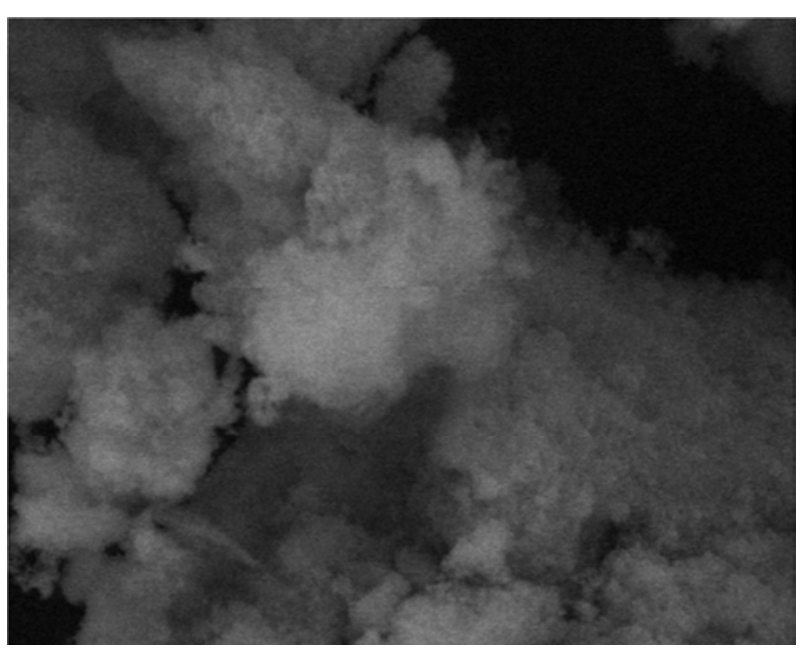

Figure 17. SEM image of P-laden $\mathrm{LDH}_{2}$

Appraisal of the FTIR spectra of both the spent (Figure 19) and raw $\mathrm{LDH}_{2}$ samples (Figure 5) indicated the appearance of new peaks in the spectra of the spent sample. Phosphate peaks were reflected at $873 \mathrm{~cm}^{-1}$ and $1047 \mathrm{~cm}^{-1}$. The phosphate peak at $1047 \mathrm{~cm}^{-1}$ attributed to the bending vibration of adsorbed phosphate was formed as a result of ion exchange between the 
surface hydroxyl groups on the LDH (M-OH) to give M-O-P, an indication of ligand exchange during the sorption process. The X-ray diffractogram of the phosphate-loaded LDH (Figure 20) was very different from that of the raw sample (Figure 2) as observed by: (i) the broad peak at $2 \theta=25-50^{\circ}$, an implication of loss of order in the structure of the layered material after phosphate uptake (ii) significant reduction in the crystallinity of the spent samples, an indication of amorphous nature of the phosphate-laden $\mathrm{LDH}_{2}$. Mineralogical composition of the phosphate laden $\mathrm{LDH}_{2}$ sample indicated the formation of whitlockite, hydroxyapatite $\left(\mathrm{Ca}_{5}\left(\mathrm{PO}_{4}\right)_{3} . \mathrm{OH}\right)$ and calcite [23-24]. Calcium - based LDHs are believed to exhibit this phenomenon due to formation of amorphous phosphate salts (precipitates) of $\mathrm{Ca}$ on the surface of the $\mathrm{LDH}$ sample during the sorption process [1]. The $\mathrm{LDH}$ readily releases $\mathrm{Ca}^{2+}$ into the liquid phase which leads to the increase in $\mathrm{Ca}^{2+}$ concentration observed after P uptake (Table 4) as a result of its high solubility product $\left(5.02 \times 10^{-6}\right)$ to precipitate with phosphate [25]. The dissolution phenomenon of the LDHs is responsible for the lost of the layered structure after phosphate uptake (Figure 20). These findings are in conformity with the removal of Ca-based LDHs for removing different $\mathrm{P}$ species in other previous studies [11, 25-28]. These findings reveal that the dual combinations of ion exchange and precipitation were the mechanisms of phosphate removal by the LDH sample.

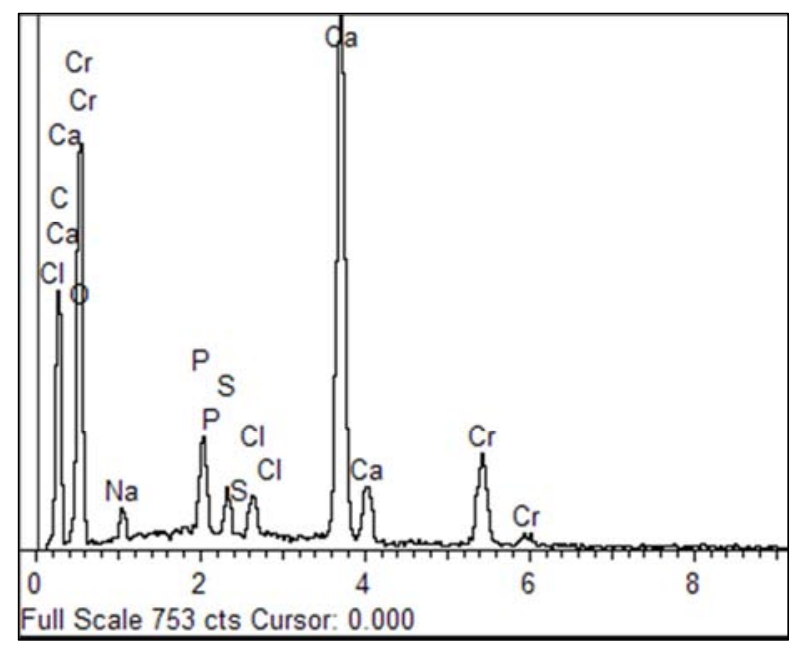

Figure 18. EDX Spectra of P-laden $\mathrm{LDH}_{2}$.

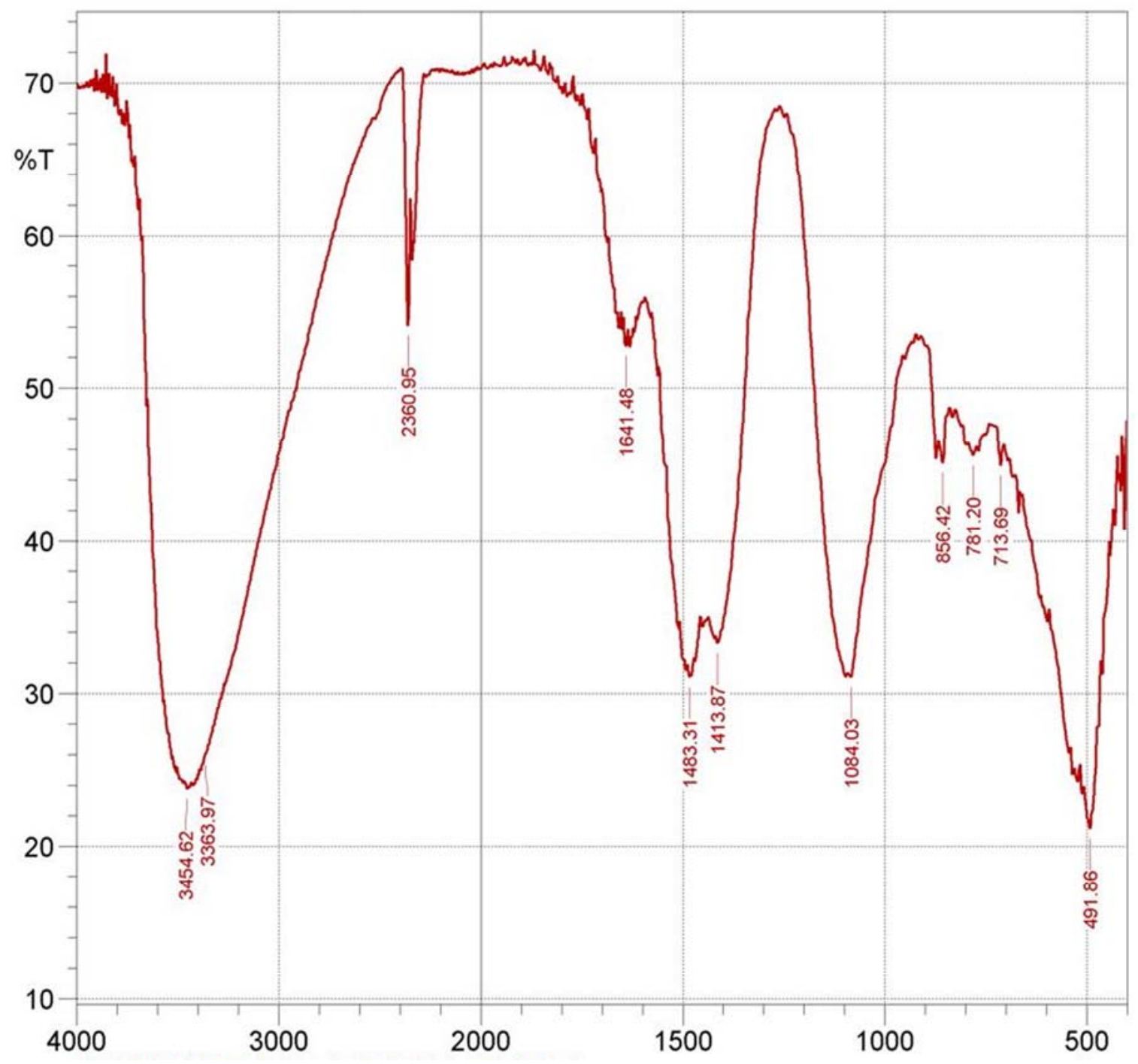

Figure 19. FTIR Spectra of $P$ - laden $\mathrm{LDH}_{2}$. 


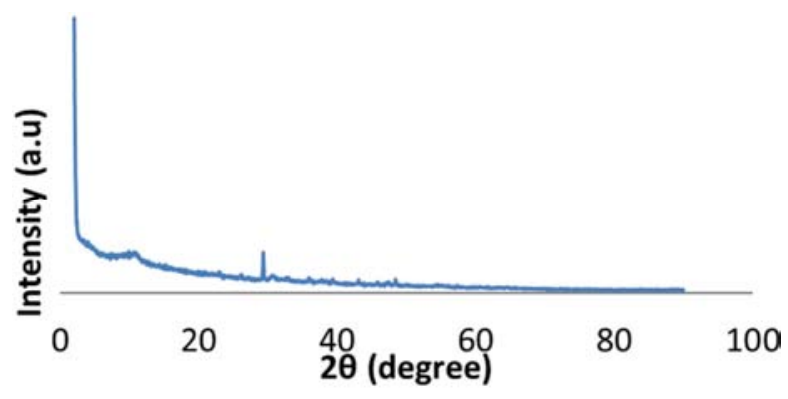

Figure 20. XRD Pattern of $P$-laden $\mathrm{LDH}_{2}$.

\section{Conclusion}

In conclusion, novel $\mathrm{CaCr} \mathrm{LDHs}$ were successfully synthesised using Gastropod shell as a biogenic precursor for $\mathrm{Ca}^{2+}$ source. The study revealed that the type and amount of divalent cation content in the LDH sample is important in the sorption capacity as adsorbent with the highest $\mathrm{Ca}$ content was most suitable for optimum removal of phosphate from aqua system. The experimental data of the sorption process fitted well into Langmuir isotherm model with a maximum monolayer sorption capacity of $142.86 \mathrm{mg} / \mathrm{l}$. Characterisation of the phosphate-loaded LDH revealed the loss of the layered structure as a result of dissolution of $\mathrm{Ca}^{2+}$ from the $\mathrm{LDH}$ and combination of ion exchange and co- precipitation as mechanisms of the removal process. The findings obtained in this study will further the development of layered double hydroxides for water/ wastewater treatment.

\section{References}

[1] Ashkuzzaman, S. M., Jiang, J. Q. 2014. Study on the sorptiondesorption regeneration performance of $\mathrm{Ca}-, \mathrm{Mg}-$, and $\mathrm{CaMg}-$ based LDHs for removing phosphate from water. Chem. Engr. Journal. 246, 97-105.

[2] Goh, K. H., Lim T. T., Dong, Z. 2008. Adsorption of phosphate by layered double hydroxide in aqueous solution. Apply Clay Sc. 32, 325-260.

[3] Cavani, F., Trifiro, F., Vaccari, A. 1991. Hydrotalcite - type anionic clays: preparation, properties and applications. Cata. Today 11, 173-301.

[4] Oladoja, N. A., Adelagun, R. O. A., Ahmad, A. L., Ololade, I. A. 2015. Phosphorus recovery from aquaculture wastewater using thermally treated gastropod shell. Process Safety and Environmental Protection 98, 296-308.

[5] Koilraj, P., Kannan, S. 2010. Phosphate uptake behaviour of ZnAlZr tenary LDH through surface precipitation. J. Colloid and Interface Sc. 341, 298-297.

[6] Chubar, N., Gerda, V., Megantari, O., Micusik, M., Omastova, M., Heister, K., Pascal, M., Fraissard, J. 2013. Applications versus properties of Mg-Al LDHs provided by their syntheses methods: Alkoxide and alkoxide - free sol-gel syntheses and hydrothermal precipitation. Chem. Engr. J. 234, 284-299.

[7] Rives, V., Ulibari, M. A. 2009 Layered double hydroxide intercalated with metal coordination compound and oxometalates. Coord. Chem. Review 181, 61-120.

[8] Chitrakar, M., Tezuka, M., Sonoda A., Sakena, K., Takahiro H. 2008. A new method of synthesis of $\mathrm{Mg}-\mathrm{Al}, \mathrm{Mg}-\mathrm{Ca}, \mathrm{Zn}-$ $\mathrm{AL}$ LDHs and their uptake properties of bromide ion. Ind. Eng. Chem. Res. 47, 4905-4908.

[9] Miyata, S. 1975. The synthesis of hydotalcite-like compounds and their structure and physic-chemical properties. Clays Clay Miner. 23, 369-375.

[10] Koilraj, P., Antonyraj, C. A., Gupta, V., Reddy, C. R. K., Kanna, S. 2013. Novel approach for selective phosphate removal using colloidal LDH nanosheets and use of residue as fertilizer. Apply Clay Sc. 86, 111-118.

[11] Sun, X., Imai, T., Sekine, M., Higuchi, T., Yamamoto, K., Kanno, A., Nakazono, S. 2014. Adsorption of phosphate using calcined $\mathrm{Mg}_{3}{ }^{-} \mathrm{Fe} \mathrm{LDH}$ on a fixed -bed column study. Ind. Engr. Chem. 20, 3623-3630.

[12] Saber, O., Tagay, H. 2005. Preparation of new LDH, Co-V. Rev. Adv. Mat. Sc. 10, 59-63.

[13] Prikhod'od R. V., Sychev, M. V., Astralin, L. M., Erdman, K., Mangel, Van Santen, R. A. 2001 Synthesis and structural transformation of hydrotalcite materials $\mathrm{Mg}-\mathrm{Al}$ and $\mathrm{Zn}-\mathrm{Al}$. Russ. J. App. Chem. 74, 1621-1626.

[14] Isaac- Paez, E. D., Leyva-Ramos, R., Jacobo-Azura, A., Martinez - Rosales, J., Flores - Cano, M. 2014. Adsorption of Boron on calcined $\mathrm{Al} \mathrm{Mg}$ layered double hydroxide from aqueous solutions: Mechanisms and effects of operating conditions. Chem. Engr. J. 245, 248-257.

[15] Cheng Xiang, Huang Xinrui, Wang Xingzu, Zhao Bingquig, Chen Aiyan, Sun Dehzi. 2009. Phosphate adsorption from seawage filtrate using Zn- Al LDHs. J. Haz. Mat. 169, 958-964.

[16] Johannson, L., and Gustafson, J. P., 2000. Phosphate removal using blast furnace slags and opoja- mechanism. Water Res. $34 ; 259-265$.

[17] Oladoja, N. A., Ahmad, A. L., Adesina, O. A. Adelagun, R. O. A., 2012. Low-cost biogenic waste for phosphate capture from aqueous system. Chem. Eng. J. 209, 170-179.

[18] Ofomaja, A. E. 2011. Evaluation of Snail shell as coagulant aid in the alum precipitation of aniline blue from aqua system. Environ. Technol. 32, 639-652.

[19] Adelagun, R. O. A., Itodo, A. U., Berezi, E. P., Oko, O. J., Kamba, E. A., Andrew, C., Bello, H. A. 2014. Adsorptive Removal of $\mathrm{Cd}^{2+}$ and $\mathrm{Zn}^{2+}$ From Aqueous System by BSG. Chemistry and Materials Research. 6, 104-112.

[20] Oladoja, N. A., Seifert, M. L., Drewes, J. E., Helmreich, B., 2017. Influence of organic load on the deflouridation efficiency of nano- magnesium oxide in groundwater. Sep. and Purif Tech. 174: 116-125.

[21] Anirudhan, T. S., Sochithra, P. S., Rijith, S., 2008. Aminemodified polyacrylamide bentonite composite for the adsorption of humic acid in aqueous solution. Colloids Sur. A. Physicochem. Eng. ASP. 326, 147-156.

[22] Palmer, S. J., Soinsard, A., Frost, R. I. 2009. Determination of the mechanism for the inclusion of arsenate, vanadate or molybdate anions into hydrotalcite with variable cationic ratio. Colloid interface Sci. 329, 404-409. 
[23] Violante A. A. A., Pucci, M., Cozzolino, V., Zhu, J., Pigna, M., 2009. Sorption/ desorption of arsenate on/from $\mathrm{Mg} / \mathrm{Al}$ Layered double hydroxide: Influence on phosphate. Colloid and Interface Sci. 333, 63-70.

[24] Goh, K. H., Lim, T. T. 2010. Influence of co-existing specie on the sorption of toxic anions from aqueous solution by nano crystalline Mg/Al LDH. J. Haz. Mat. 180, 401- 408.

[25] Xu Yunfeng, Lv Huafang, Qian Guangren, Zhang Jia, Zhou Ji Zhi. 2014. Dual removal process of phosphate on Ca- LDH with substitution with Fe or AL. J. Haz. Toxic Radioactive Waste 18, 1-8.
[26] Wu, Y., Chi, Y., Baig, Cao, Y., Zhou, J., Xu, Y., Liu, Q., Xu, Z., Xu, P., Qiao, S. 2010. Effective removal of selenate from aqueous solution by the Friedel phase. J. Haz. Mat. 176, 193198.

[27] Zhou, J., Cheng, Y., Yu, J., Liu, G. 2011. Hierarchically porous calcined lithium/ aluminum layered double hydroxides: facile synthesis and enhanced adsorption towards fluoride in water. J. Mater. Chem. 21, 19353-19361.

[28] Zhou, J., Xu, Z. P., Qiao, S., Liu, Q., Xu, Y., Qian, G. 2011. Enhanced removal of triphosphate by $\mathrm{MgCaFe}-\mathrm{Cl}-\mathrm{LDH}$ : synergism of precipitation with intercalation and surface uptake. J. Hazard. Mater. 189, 586-594. 